\title{
Prevalence of Distal Carious Lesions in Mandibular Second Molars Due to Mesio-Angular Impacted Third Molars
}

\author{
Talha Ashar ${ }^{1}$ \\ BDS, FCPS \\ Asma Shakoor ${ }^{2}$ \\ BDS, MSc, MFDSRCS \\ Sadia Ghazal ${ }^{3}$ \\ BSc, M.S \\ Naghma Parveen ${ }^{4}$ \\ Muhammad Nasir Saleem ${ }^{5}$ \\ BDS, MCPS, FCPS \\ Hina Zafar Raja ${ }^{6}$ \\ BDS, FCPS, MSc \\ BDS, FCPS, MSc
}

OBJECTIVE: This study was conducted to observe the relationship of mesio-angular impacted third molars to the development of distal caries in adjacent second molars.

METHODOLOGY: This cross-sectional study was conducted at Nishtar Institute of Dentistry, Multan. Nine hundred and eighty nine periapical, bitewing and Panoramic radiographs were recorded and examined for distally carious second molars and impacted mandibular third molars. SPSS version 23.0 was used for data entry and analysis.

RESULTS: Almost $40.8 \%$ of the target population reported with distal caries due to third molar impactions. A total of $53.30 \%$ of these impactions were of the mesio-angular variety. No distal caries was detected in transverse type of impactions.

CONCLUSION: The current study concluded that the prevalence of distal caries in mandibular second molars and the positioning of adjacent impacted mandibular third molars in the dental arch were interlinked. Consequently, extraction of mandibular third molars should be considered to prevent caries and premature loss of second molar teeth.

KEYWORDS: Distal caries, Impacted third molar, Infections, Risk Factor

HOW TO CITE: Ashar T, Shakoor A, Ghazal S, Parveen N, Saleem MN, Raja HZ. Prevalence of distal carious lesions in mandibular second molars due to mesio-angular impacted third molars. J Pak Dent Assoc 2021;30(1):50-55.

DOI: https://doi.org/10.25301/JPDA.301.50

Received: 09 November 2020, Accepted: 17 December 2020

\section{INTRODUCTION}

$\mathrm{T}$ hird molars usually erupt in the oral cavity at the age of 15 to 24 years. Some erupt in the late 30 s, while others remain unerupted. ${ }^{1,2}$ The time of eruption, position in the arch and size of the crown varies among individuals. Third molars are considered as impacted when they fail to erupt into a functional occlusion in the oral cavity at a specified time. ${ }^{3}$ These impactions are classified according to angulations in the arch, mandibular bone position

1. Assistant Professor, Department of Operative Dentistry, Nishtar Institute of Dentistry, Multan, Pakistan.

2. Associate Professor, Department of Community \& Preventive Dentistry, Institute of Dentistry, CMH Lahore Medical College

3. Dental Technologist, Tehsil Headquarter Hospital Mian Channo.

4. Associate Professor, Department of Operative Dentistry, Nishtar Institute of Dentistry, Multan, Pakistan.

5. Professor, Department of Operative Dentistry, Institute of Dentistry, CMH Lahore Medical College, Lahore, Pakistan.

6. Professor, Department of Prosthodontics, Institute of Dentistry, CMH Lahore Medical College, Lahore, Pakistan.

Corresponding author: "Dr. Asma Shakoor” < asmashakoor@ hotmail.com > and crown patterns. ${ }^{3}$ Pell GJ and Gregory GT devised a comprehensive system to classify impacted wisdom teeth.4Winters categorized the third molars into mesio-angular, disto-angular, horizontal, and vertical impactions - depending on tooth angulation in the oral cavity. ${ }^{5}$

Previous literature showed a high rate of carious lesions in the second molars due to impaction of third molars. ${ }^{6,7}$ Majority of the distal caries was linked to mesio-angular tilting of third molar teeth. ${ }^{7,8}$ Peri-coronal flap makes this area less accessible for routine cleaning and more prone to biofilm and plaque accumulation. ${ }^{9}$ Gingival recession further accelerates the process by allowing food impaction and exposure of cementoenamel junction. Carious lesions initiate and progress as a consequence. ${ }^{10}$ Pain is the most significant indicator in the detection of caries of this variety. ${ }^{11}$ These lesions often remain unnoticed for long periods of time due to poor visibility. Delay in treatment of distal carries is one of the lead causes of early tooth loss. ${ }^{12}$

A similar study was carried out in Islamabad, Pakistan with the findings that $42.5 \%$ of distal caries in mandibular 
Ashar T/ Shakoor A/ Ghazal S/

Parveen N/ Saleem MN/ Raja HZ

second molars developed due to adjacent impacted third molars. A total of 200 patients with impacted third molars were included in the study. ${ }^{13}$

Another study conducted in Lahore showed the pattern of mandibular third molar impaction and its complications. This study concluded that mesio-angular third molar impaction was most common type of impactions responsible for the occurrence of dental caries in adjacent molars. ${ }^{14}$

Distal caries in mandibular second molars due to mesially tilted impacted third molars is a tremendous public health concern which needs to be addressed. ${ }^{15}$ Various studies prove that early extraction of third molars can prevent this; thereby arresting premature tooth loss. ${ }^{16,17}$ There is a lack of local research on the occurrence of distal caries in mandibular second molar due to third molar impactions. There is a need to observe this occurrence especially within the population visiting dental hospital in Multan. A study was required to know the effects of impaction in geographically diverse area such as Multan. Thus, the rationale of this study was evaluate the relationship of distal caries in mandibular second molars to mesio-angular impacted third molars.

The aims of this study were to;

a) Assess the prevalence of distal caries in mandibular second molars.

b) Assess the relationship between the type of impaction of mandibular third molars and distal caries in adjacent mandibular second molars.

\section{METHODOLOGY}

A cross-sectional survey was conducted at Nishtar Institute of Dentistry, Multan for the duration of eight months. An ethical review committee provided the approval for the study (Ref. 9972/NID). Patients were informed of the goals of the study and their consent was taken. All the patients referred for pain in the second molar region were provisionally diagnosed with proximal caries due to third molar impactions. Concise patient history forms were recorded. After clinical examination, patients aged between 17 to 35 years underwent periapical and bitewing $\mathrm{x}$-rays for assessment and diagnosis of distal caries in mandibular second molars. Panoramic radiographs were used to analyse the angulation of impaction of third molars. A sample of 989 patients - allocated by convenience sampling - was considered for the purpose of this study. A confidence interval of $95 \%$ and absolute precision of 5\% was established. Taking into account a dropout rate of $10 \%$, the sample was inflated by $10 \%$ accordingly. Patients with missing mandibular 2nd molars, systemic diseases and severe periodontitis were excluded from the study. Mandibular third molars were classified as vertical,
Prevalence of distal carious lesions in mandibular second molars due to mesio-angular impacted third molars

mesioangular, distoangular and horizontal according to the Pell GJ and Gregory GT classification system. ${ }^{4}$ Three clinicians evaluated periapical and bitewing radiographs at different times for detection of distal carries and third molar impactions. An agreement of two or more observers was considered confirmatory for the diagnosis to eliminate any potential bias. It also supported inter examiner reliability. The study had two variables of interest pertinent to the objectives i.e. "Presence/absence of distal caries" and "Presence/absence of third molar impaction". Data was analysed using SPSS version 23. Descriptive statistics were applied to assess data in frequencies. Prevalence of distal caries and third molar impactions was displayed in graphs. Mean, standard deviation and percentage values were used to analyse and assess data.

\section{RESULTS}

A total of 989 patients exhibiting impacted mandibular third molars were assessed for the purpose of this study. Amongst them, 408 patients $(40.8 \%)$ were diagnosed with distal caries in mandibular second molars and included in further analysis. Table 1 presents basic data of the study participants. There were more female patients than that of

Table 1: Basic demographics

\begin{tabular}{|l|cllll}
$\begin{array}{l}\text { Mesio-angular } \\
\text { impaction }\end{array}$ & $\begin{array}{l}\text { Disto-angular } \\
\text { impaction }\end{array}$ & $\begin{array}{l}\text { Vertical } \\
\text { impaction }\end{array}$ & $\begin{array}{l}\text { Horizontal } \\
\text { impaction }\end{array}$ & $\begin{array}{l}\text { Transverse } \\
\text { impaction }\end{array}$ \\
\hline $\mathbf{3 2 . 8 4} \%(\mathbf{1 3 4})$ & $\mathbf{2 1 . 8} \%(\mathbf{8 9 )}$ & $\mathbf{1 8 . 8} \%(\mathbf{7 7})$ & $\mathbf{2 4 . 2} \%(\mathbf{9 9 )}$ & $\mathbf{2 . 2} \%(\mathbf{9 )}$
\end{tabular}

males. This indicated a higher risk of second mandibular molars distal caries in females. Unilateral impactions were less common than bilateral impactions of mandibular third molars. Data analysis revealed 66\% impactions on both sides of the dental arch with $34 \%$ limited to one side only. Mandibular third molars were most commonly impacted in a mesio-angular dimension.

Table no 2 presents patient data segregated according to age groups as follows;

Group 1: 17 to 22 years of age.

Group 2: 23 to 29 years of age.

Group 3: 30 to 35 years of age.

In this study, five different types of mandibular third molar impactions were discussed. Their prevalence and

Table 2: Age Groups and distal caries prevalence

\begin{tabular}{|lllllll|} 
& \multicolumn{2}{c}{ Group 1 } & \multicolumn{2}{c}{ Group 2 } & \multicolumn{2}{c|}{ Group 3 } \\
\hline Total & \multicolumn{2}{c}{ 137(33.08\%) } & \multicolumn{2}{c}{ 162(39.7\%) } & \multicolumn{1}{l|}{ 109(27.2\%) } \\
& Female & Male & Female & Male & Female & Male \\
& 86 & 51 & 86 & 76 & 52 & 57
\end{tabular}


Ashar T/ Shakoor A/ Ghazal S/

Parveen N/ Saleem MN/ Raja HZ

association with distal caries was described in Table no 2 . Mesioangular impacted third molars caused the highest incidence of distal caries in second mandibular molars. On the other hand, no caries was observed in transverse impactions.

Figure 1: Gender Distribution

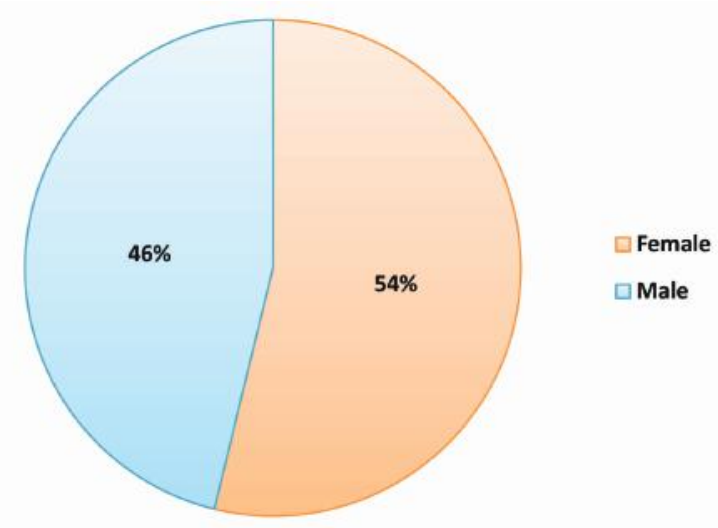

Figure 2: Prevalence of distal caries in different age groups

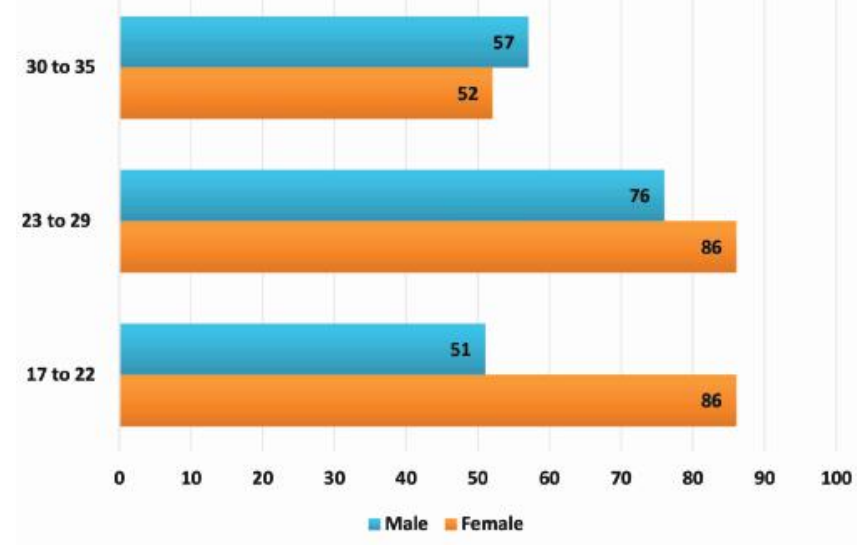

Figure 3: Distribution of unilateral and bilateral impaction of mandibular third molar

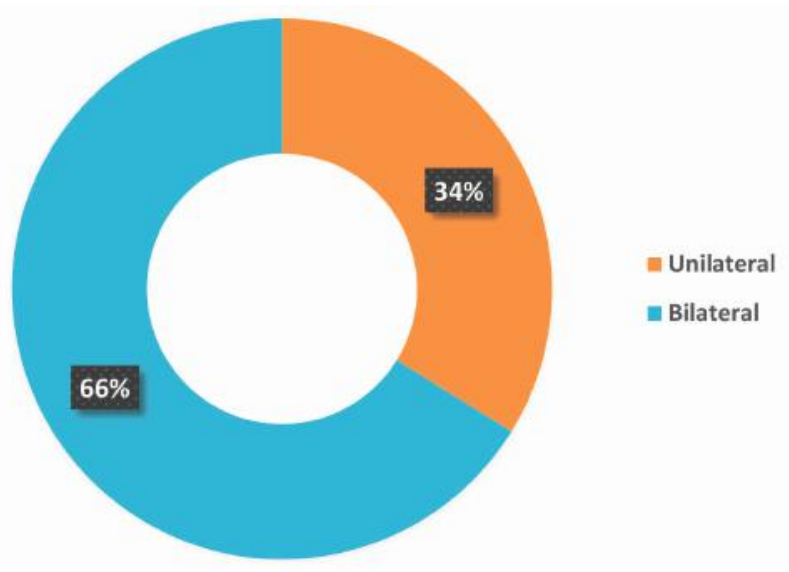

Prevalence of distal carious lesions in mandibular second molars due to mesio-angular impacted third molars

Figure 4: Angulation of impacted 3rd Molar

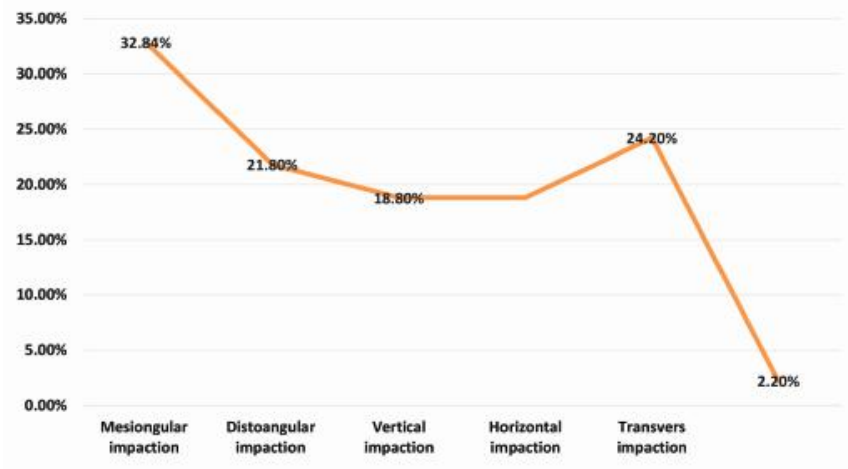

Figure 5: Prevalence of distal caries

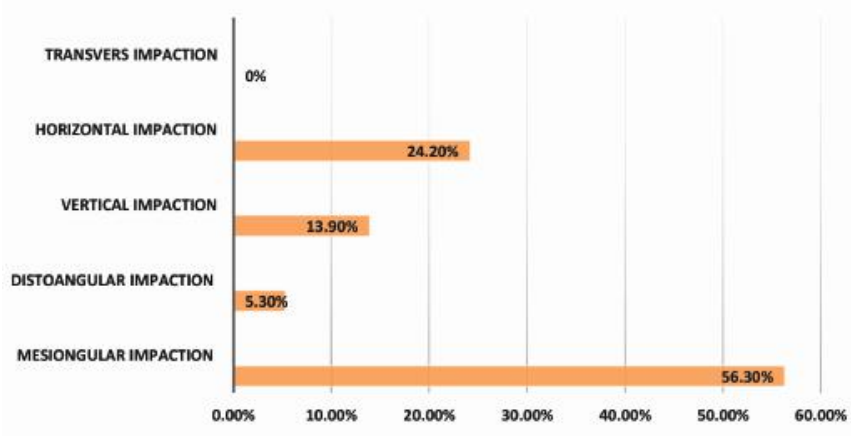

\section{DISCUSSION}

An impacted tooth may be defined as a tooth that does not reach the occlusal plane despite two thirds of its root development. Mandibular third molars are the most frequently impacted teeth. ${ }^{18,19}$ Development of third molar impactions can be attributed to a number of etiological factors. ${ }^{20}$ These factors include lack of space, retardation of facial growth, late third molar mineralization, distal direction of eruption, early physical maturity, or lack of sufficient eruption force, blockade by physical/mechanical barriers, such as scar tissue, fibromatosis, compact bone, odontogenic cyst, and tumors. ${ }^{20}$ The prevalence of impacted third molars has been shown to vary in different populations and ethnicities ranging from $9.6 \%$ to $68.5 \% .^{21,22}$ These impactions, however, tend to be nearly equally distributed across the two genders in many of the earlier studies with slightly increased frequency in females according to some. ${ }^{22-24}$ The present study also found similar results with regards to the gender predilection of impacted third molars. There were 54\% females and $46 \%$ males with impacted third molars. This can be attributed to the growth pattern differences between the two genders. The growth of mandible in males, continues during the root development of the mandibular third molars giving a chance for these teeth to erupt in the oral cavity. A slightly increased frequency of impacted mandibular third molars in females 
Ashar T/ Shakoor A/ Ghazal S/ Parveen N/ Saleem MN/ Raja HZ

may be due to an early cessation of jaw growth in this this gender group. This explanation, however, caters to only a single etiological factor of impactions in third molars namely the lack of space.

In the mandible, the impacted third molars tend to occur more frequently bilaterally than unilaterally. This has been shown by some earlier studies ${ }^{23,25,26}$ and is consistent with our findings of $66 \%$ bilateral occurrence versus a $34 \%$ unilateral presentation. This can also be explained on the basis of the fact that the local reasons for impacted third molars like lack of space tend to affect both sides in an individual at a certain stage of his/her jaw development. Third molar impactions can be classified in different ways. One of the most commonly employed classification is the Winter classification based on the angle formed by the long axis of the third molar and the second molar. ${ }^{27}$ This was the classification system used in present study categorizing impactions as mesio-angular, disto-angular, vertical, horizontal and transverse. The most common type of third molar impaction according to our findings was mesio-angular impaction which is in line with most earlier studies from different populations and ethnic backgrounds. ${ }^{23,24}$ An earlier study conducted in Pakistani population also identified mesio-angular impaction as the most prevalent type of mandibular third molar impaction. ${ }^{28}$

Impacted third molars have been associated with a variety of different pathological conditions. These conditions include pericoronitis, caries, food lodgment, pocket formation, periodontal bone loss, root resorption of adjacent teeth, and development of cysts and tumors. ${ }^{28-30}$ The frequency of dental caries in teeth adjacent to impacted third molars has been reported to be as low as 1 to $4.7 \%{ }^{31,32}$ to as high as $15-51 \%^{18,33-35}$ in some of the earlier studies. Our study has showed similar trend with $40.8 \%$ of distal surface of second molars affected by dental caries. Very similar results were obtained from an earlier study on Pakistani population exhibiting $42.5 \%$ of second molars affected by distal caries in the presence of an impacted third molar. ${ }^{33}$ Dental caries is a multifactorial disease that can increase in its frequency in individuals with local areas of food impaction. This facilitates the accumulation of dental plaque containing cariogenic bacteria due to the inability of the normal cleaning aids to access these areas.

The highest prevalence of dental caries in our study $(56.3 \%)$ was associated mesio-angular impaction followed by the horizontal impactions (24.2\%). This is in accordance with many other studies displaying similar trend. ${ }^{33,36-38} \mathrm{An}$ earlier study on Pakistani population also exhibited similar trend with mesio-angular and horizontal impactions displaying $41 \%$ and $27 \%$ distal caries respectively. ${ }^{33}$ Both mesio angular and horizontal impactions can form plaque accumulating
Prevalence of distal carious lesions in mandibular second molars due to mesio-angular impacted third molars

crevices resulting in the distal caries in second molars. A change in the microbial flora and inflammatory mediators has been proposed by earlier study around impacted third molars strengthening this view point further. ${ }^{37}$

Cervical caries in surfaces adjacent to the impacted teeth can display carious lesions due to the abnormal contact between the most mesial surface of the impacted third molars and the distal surface of mandibular second molars. The area of contact of impacted third molar with the second molar has also been explored in some earlier studies with contact at the amelocemental junction being the most susceptible. This is an aspect not covered in our study that can have meaningful clinical implications. Based on the findings of our study, second molar teeth adjacent to mesio angularly and horizontally impacted third molars should be closely either prophylactically removed or followed up closely.

\section{LIMITATIONS}

The first limitation of the study was a constrained sample size. This can be overcome by conducting the review on a larger scale with an increased number of patients. However, this is time consuming and requires a greater number of qualified dentists. The second limitation was the radiographic technique. In the current study, OPG, periapical and bitewing radiographs were used for assessment and diagnosis. CBCT is a more effective diagnostic tool for presurgical analysis. It eliminates errors of magnification, superimposition and image distortion. Three dimensional imaging allows clear identification of important anatomic landmarks like mandibular canal, mental foramen and maxillary sinus. Additional information such as the thickness of cortical plate, cancellous bone patterns, fenestrations, and roots inclinations can be obtained with the help of CBCT prior to surgical entry.

\section{CONCLUSION}

The current study concluded that the prevalence of distal caries in mandibular second molars and the positioning of adjacent impacted mandibular third molars in the dental arch were interlinked. This relationship provides a favourable environment for the initiation and progression of distal caries in mandibular second molars. Among all types of third molar impactions, mesio-angular type provides the most favourable space and niche for the colonization of microbes leading to distal caries in the adjacent second molar.

\section{CONFLICT OF INTEREST}

The authors declare that there is no conflict of interest. 
Ashar T/ Shakoor A/ Ghazal S/ Parveen N/ Saleem MN/ Raja HZ

This study was not funded by any organization or institute.

\section{REFERENCES}

1. Ventä I, Schou S. Accuracy of the Third Molar Eruption Predictor in predicting eruption. Oral Surg Oral Med Oral Pathol Oral Radiol Endod. 2001; 91:638-42. https://doi.org/10.1067/moe.2001.113350

2. Kruger E, Murray W, Thomson, MA, Konthasinghe P. Third molar outcomes from age 18 to 26: Findings from a population-based New Zealand longitudinal study. Oral Surg Oral Med Oral Pathol Oral Radiol Endod. 2001; 92:150-55.

https://doi.org/10.1067/moe.2001.115461

3. Breik O, Grubor D. The incidence of mandibular third molar impaction in different skeletal face types. Aust Dent J. 2008; 53: 320-24.

https://doi.org/10.1111/j.1834-7819.2008.00073.x

4. Pell GJ, Gregory GT. Impacted mandibular third molars: Classification and modified technique for removal. The Dental Digest. 1933; 39:33038 .

5. Obimakinde, OS. Impacted mandibular third molar surgery; an overview. A publication by the dentiscope editorial Board .2009; 16:2224.

6. Faculty of Dental Surgery of the Royal College of Surgeons of England FDS response to NICE review 2014 of guidance on the extraction of wisdom teeth. 2015. Online information available at https://www.rcseng.ac.uk/fds/policy/documents/nice-reviewof guidanceon-wisdom-teeth-extraction-fds-response-with-appendices/view (accessed March 2015).

7. McArdle LW, Renton TF. Distal cervical caries in the mandibular second molar: an indication for the prophylactic removal of the third molar? Brit J Oral Maxillofac Surg 2006;44:42-5.

https://doi.org/10.1016/j.bjoms.2005.07.025

8. Toedtling V, Yates JM. Revolution vs status quo? Non-intervention strategy of asymptomatic third molars cause harm. Brit Dent J. 2015; 219: 11-12.

https://doi.org/10.1038/sj.bdj.2015.525

9. Chu FC, Li TK, Lui VK, Newsome PR, Chow RL, Cheung LK. Prevalence of impacted teeth and associated pathologies- A radiographic study of the Hong Kong Chinese population. Hong Kong Med J. 2003; 9:158-63.

10. BDA evidence summary. Second molar distal caries; 2013 (cited June 2013). Available from http://www.bda.org/dentists

11. Mansoor J, Jowett A, Coulthard P. 'NICE or not so NICE?' Brit Dent J. 2013; 215: 209-212.

https://doi.org/10.1038/sj.bdj.2013.832

12. Krishnan B, Mohammad Hossni El Sheikh, Rafa El-Gehani, Orafi $\mathrm{H}$. Indications for removal of impacted mandibular third molars: A
Prevalence of distal carious lesions in mandibular second molars due to mesio-angular impacted third molars

single institutional experience in Libya. J Maxillofac Oral Surg. 2009; 8:246-48.

https://doi.org/10.1007/s12663-009-0060-5

13. Sheikh AZ,Riaz M,Shafiq S. Incidence of distal caries in mandibular second molars due to impacted third molars - A clinical \& radiographic study. Pak Oral Dent J.2012;32:364-70.

14. Rauf S, Ali W, Chaudhry R, Kazmi SS, Imtiaz M. Pattern of mandibular third molar impaction: a radiographic study. Pak Oral Dent J 2019; 39:238-42.

15. American Association of Oral and Maxillofacial Surgeons (AAOMS). Age-Related Third Molar Study. J Oral Maxillofac Surg 2005; 63: 1106-114.

https://doi.org/10.1016/j.joms.2005.04.022

16. American Association of Oral and Maxillofacial Surgeons (AAOMS) Conventional Wisdom about Wisdom Teeth Confirmed: Evidence shows keeping wisdom teeth may be more harmful than previously thought. 2010. Online information available at http://www.aaoms.org/ (accessed May 2015).

17. Chu FC, Li TK, Lui VK, Newsome PR, Chow RL, Cheung LK. Prevalence of impacted teeth and associated pathologies- A radiographic study of the Hong Kong Chinese population. Hong Kong Med J. 2003; 9:158-63.

18. van der Linden W, Cleaton-Jones P, Lownie M. Diseases and lesions associated with third molars: Review of 1001 cases. Surg, Oral Med, Oral Pathol, Oral Radiol, Endodontol. 1995;79: 142-45.

https://doi.org/10.1016/S1079-2104(05)80270-7

19. Bishara SE, Andreasen G. Third molars: a review. American J Orthod. 1983;83:131-37.

https://doi.org/10.1016/S0002-9416(83)90298-1

20. Haidar Z, Shalhoub SY. The incidence of impacted wisdom teeth in a Saudi community. Int J Oral maxillofac Surg. 1986;15: 569-71.

https://doi.org/10.1016/S0300-9785(86)80060-6

21. Hatem M, Bugaighis I, Taher EM. Pattern of third molar impaction in Libyan population: A retrospective radiographic study. The Saudi J Dent Res. 2016;7:7-12.

https://doi.org/10.1016/j.sjdr.2015.04.005

22. Quek S, Tay C, Tay K, Toh S, Lim K. Pattern of third molar impaction in a Singapore Chinese population: a retrospective radiographic survey. Int J Oral and Maxillofac Surg. 2003;32:548-52. https://doi.org/10.1016/S0901-5027(03)90413-9

23. Rezaei F, Imani MM, Khavid A, Nabavi A. Patterns of Mandibular Third Molar Impaction in an Iranian Subpopulation. Pesquisa Brasileira em Odontopediatria e Clínica Integrada. 2020;20:5411. https://doi.org/10.1590/pboci.2020.099

24. Eshghpour M, Nezadi A, Moradi A, Shamsabadi RM, Rezaei NM, Nejat A. Pattern of mandibular third molar impaction: A cross-sectional 
Ashar T/ Shakoor A/ Ghazal S/ Parveen N/ Saleem MN/ Raja HZ

study in northeast of Iran. Niger J Clin Pract. 2014;17:673-7. https://doi.org/10.4103/1119-3077.144376

25. Guthua S, Mwaniki D. A retrospective study of characteristics of impacted mandibular wisdom teeth in 110 patients treated in Nairobi, Kenya. African dental journal: official publication of the Federation of African Dental Associations J dent Africa. 1992; 6:30-3.

26. Ramamurthy A, Pradha J, Jeeva S, Jeddy N, Sunitha J, Kumar S. Prevalence of mandibular third molar impaction and agenesis: a radiographic south Indian study. J Ind Acad Med Radiol. 2012; 24:7.

https://doi.org/10.5005/jp-journals-10011-1289

27. Winter GB. Impacted mandibular third molar. St Louis: American Medical Book. 1926;41.

28. Ishfaq M, Wahid A, Rahim AU, Munim A. Patterns and presentations of impacted mandibular third molars subjected to removal at Khyber college of dentistry Peshawar, Pak. Oral Dent J. 2006;26:221-26.

29. Al-Anqudi SM, Al-Sudairy S, Al-Hosni A, Al-Maniri A. Prevalence and Pattern of Third Molar Impaction: A retrospective study of radiographs in Oman. Sultan Qaboos University Medi J. 2014; $14: \mathrm{e} 388$.

30. Stanley H, Alattar M, Collett W, Stringfellow Jr H, Spiegel E. Pathological sequelae of "neglected" impacted third molars. J Oral Pathol Med. 1988;17:113-17.

https://doi.org/10.1111/j.1600-0714.1988.tb01896.x

31. Daley TD. Third molar prophylactic extraction: a review and analysis of the literature. Gen Dent. 1996;44:310.
Prevalence of distal carious lesions in mandibular second molars due to mesio-angular impacted third molars

32. Song F, O Meara S, Wilson P, Golder S, Kleijnen J. The effectiveness and cost-effectiveness of prophylactic removal of wisdom teeth: NHS Centre for Reviews and Dissemination; 2000.

https://doi.org/10.3310/hta4150

33. Sheikh MA, Riaz M, Shafiq S. Incidence of distal caries in mandibular second molars due to impacted third molars-A clinical and radiographic study. Pak Oral Dent J. 2012;32t.

34. Oderinu OH, Adeyemo WL, Adeyemi MO, Nwathor O, Adeyemi MF. Distal cervical caries in second molars associated with impacted mandibular third molars: a case-control study. Elsevier; 2012. https://doi.org/10.1016/j.oooo.2012.03.039

35. Rahman NA, Daud MKM, Yaacob MF, Yusoff A. Mandibular Third Molar Impaction and Dental Caries among Patients Attending Hospital Universiti Sains Mslaysia (HUSM). Int Medi J. 2009;16:53-6.

36. Knutsson K, Brehmer B, Lysell L, Rohlin M. Pathoses associated with mandibular third molars subjected to removal. Oral Surg, Oral Med, Oral Pathol, Oral Radiol, Endodontol. 1996;82: 10-7.

https://doi.org/10.1016/S1079-2104(96)80371-4

37. Blondeau F, Daniel NG. Extraction of impacted mandibular third molars: postoperative complications and their risk factors. J Canadian Dent Assoc. 2007;73:325-325e

38. Sursala M, Blaeser B, Magalnick D. Third molar surgery and associated complication. Oral Maxillofacial Surg Clin North Am. 2003;15:177-86.

https://doi.org/10.1016/S1042-3699(02)00102-4 